\title{
CHARACTERISTICS OF SHARED MOBILITY IN BANGALORE, INDIA
}

\author{
GARGI GHOSH \\ Sky Group, India
}

\begin{abstract}
Shared mobility modes have become a common feature in the mobility scenario in urban areas throughout the world. Bike sharing systems have been in existence in Europe and various parts of North America since the 1990s in various forms like public bike sharing, closed campus bike sharing and peer to peer bike sharing. More recently technological advances have led to the entry of dockless bikes, e-bikes, e-scooters, motorised scooters and motorised e-scooters in the mobility market attempting to solve the problems of urban transport. Numerous studies have captured the characteristics and henceforth the impacts and benefits of such systems. At present, mobility in India is heavily car dominant and efforts are being made to popularise public transport and shift the balance towards a sustainable mode choice. In this context shared modes of transport have made entry in the urban transport landscape in India. On-demand car sharing services, bike-share and more recently scootershare have become an integral part of mobility in urban areas. Bangalore has also seen the foray of such services and at present they are an increasingly common sight. However, the development is fairly recent and there is a lack of literature on the characteristics of shared mobility in Bangalore. This paper attempts to document the characteristics of shared mobility in the city. Data collected from secondary and primary sources have been used to analyse the mobility characteristics.

Keywords: shared mobility, bike share, ride share, car share, ride splitting, ride sourcing, Bangalore.
\end{abstract}

\section{INTRODUCTION}

Shared mobility is a relatively new entrant in the Indian mobility market. The services offered at present consist of ride-hailing, ride-sharing, ride-splitting and bike-sharing services. Currently, the strength of shared mobility fleet in the country is two million units. Total revenue from ride-hailing services is valued at $\$ 22.40$ billion, and is expected to grow at a CAGR of $13.7 \%$ over the 2019-2025 period [1]. India is one of the largest economies of the world with a population of 135 crores [2] (1.35 billion) people of which about 34\% [3] live in urban areas. Indian cities are currently witnessing increasing ownership of private vehicles and decreasing use of public and non-motorized transport [4]. These trends have implications on India's energy consumption, energy security and economy [5], pollution, congestion, health, and safety. The transportation sector alone accounts for $18 \%$ of India's commercial energy consumption and is highly dependent on oil imports [6]. Hence, the environmental and economic implications of shared mobility in the Indian landscape are profound.

As India transits through the inflection point in mobility sector, an increased awareness and documentation is required to enable a planned inclusion of shared mobility in the transportation landscape of the country. The Motor Vehicles (Amendment) Act, 2019 of India has given statutory recognition to shared mobility providers. However, detailed policy and planning guidelines for the sector is absent. Insights into the shared mobility characteristics would aid in making supportive planning and transportation policies. There exists ample literature in Europe and America, documenting characteristics and multi-faceted impacts of shared mobility. Similar works in the Indian context is limited.

The present paper aims to capture the characteristics of share mobility in Bangalore city. The objectives of the paper in this direction is to (i) To understand the user/customer profile 
of shared mobility in Bangalore; and (ii) To understand the trip characteristics of shared mobility in Bangalore.

\section{LITERATURE REVIEW}

Shared mobility can be defined in terms of the vehicle-type, usage types, business model or technology. Shared mobility is an "umbrella" term that refers a broad array of innovative transportation modes with different use cases, business models, and travel behaviour impacts [7]. The market for personal mobility is being changed quickly due to structural modifications [8] of the social and cultural trends, as well as technological advances such as smartphones, Internet of Things (IoT), Big Data, Cloud Computing, information processing, and widespread data connectivity. Shared mobility is an innovative transportation concept, which can be considered as a set of disruptive mobility services [9] enabling urban trip planning, booking, real-time information, and fare payment into a single-user interface.

Shared mobility literature can be studied with respect to the vehicle types, the technology, business model and operational models. The present paper concentrates on the operational models of shared mobility as it is more relevant to the present study context. The various types of shared mobility service models in use are shown in Table 1.

Table 1: Types of shared modes.

\begin{tabular}{|l|l|}
\hline Shared mode type & Definition \\
\hline $\begin{array}{l}\text { Ride sourcing/Ride } \\
\text { hailing/e-Hailing }\end{array}$ & $\begin{array}{l}\text { Use of online platforms to connect passengers with drivers } \\
\text { and automate reservations, payments, and customer feedback. } \\
\text { Riders can choose from a variety of service classes, including } \\
\text { drivers who use personal, non-commercial, vehicles; } \\
\text { traditional taxicabs dispatched via the providers' apps, and } \\
\text { premium services with professional livery drivers and } \\
\text { vehicles. Ride sourcing has become one of the most } \\
\text { ubiquitous forms of shared mobility [10]. }\end{array}$ \\
\hline $\begin{array}{l}\text { Ride sharing/Car } \\
\text { sharing/Self-drive }\end{array}$ & $\begin{array}{l}\text { Ride sharing involves adding passengers to a private trip in } \\
\text { which driver and passengers share a destination. Such an } \\
\text { arrangement provides additional transportation options for } \\
\text { riders while allowing drivers to fill otherwise empty seats in } \\
\text { their vehicles [10]. }\end{array}$ \\
\hline Ride splitting & $\begin{array}{l}\text { A type of ride sourcing that allows customers requesting a ride } \\
\text { for one or two passengers to be paired in real time with others } \\
\text { traveling along a similar route [10]. }\end{array}$ \\
\hline Bike/Scooter sharing & $\begin{array}{l}\text { Short-term bike rental, usually for individual periods of an } \\
\text { hour or less over the course of a membership (periods which } \\
\text { can range from a single ride, to several days, to an annual } \\
\text { membership). Information technology-enabled public bike } \\
\text { sharing provides real-time information about the location and } \\
\text { demand for bikes at docking stations throughout a community } \\
\text { [10]. }\end{array}$ \\
\hline
\end{tabular}

The characteristics of shared mobility, its impact on infrastructure, policy and planning guidelines are widely documented for Europe, USA and China through survey based studies. A questionnaire based survey of public bike sharing in Toronto, Montreal, Washington DC and Minneapolis was conducted by UC Berkeley in 2012 also captured the user and trip 
profile and insights into the benefits of shared mobility. An exploratory survey using intercept survey at key locations in San Francisco was conducted in 2016 to determine the factors of inclination towards shared mobility services.

The European Union project momo Car-Sharing, 2010 [11] captures the state of the carsharing market including customer and service provider profile through a questionnaire based survey of 218 services providers in Europe as well as private and business customer of these services. Fondazione Politecnico di Milano (The Polytechnic University of Milan) along with Università Cattolica del Sacro Cuore (Catholic University of the Sacred Heart) [12] conducted an expansive survey of 3,758 shared mobility service users in Milan to capture similar characteristics in the city.

Documentation of shared mobility profile is at a nascent stage in India. A market analysis report on shared mobility in India was conducted in 2019 highlights the market share and the future market size of the shared mobility services. A report by the Government of India on shared mobility in India is also one of the first official documents in this subject. A questionnaire based survey approach has been adopted to capture the characteristics of shared mobility in Bangalore.

\subsection{Shared mobility market in Bangalore}

The Bangalore shared mobility market consists of ride-sharing, ride-sourcing, ride-splitting and bike-sharing service providers. Table 2 lists the various service providers in Bangalore and the nature of the services provided by them.

Table 2: Shared mobility service providers in Bangalore city.

\begin{tabular}{|l|l|l|l|}
\hline S1 & Service provider & Type of service & Type of vehicles \\
\hline 1 & ola & Ridesourcing, Ride splitting & Autorikshaw, Car, motorbikes \\
\hline 2 & uber & Ridesourcing, Ride splitting & Autorikshaw, Car \\
\hline 3 & bounce & Ride sharing, Bike sharing & $\begin{array}{l}\text { Scooters, bicycles, e-scooters, } \\
\text { e-bicycles }\end{array}$ \\
\hline 4 & yulu & Bike sharing & Bicycle, e-bicycle \\
\hline 5 & ontrack & Bike sharing & Motorbike \\
\hline 6 & namma cycle & Bike sharing & Bicycle \\
\hline 7 & twic & Bike sharing & Motorbike \\
\hline 8 & quick ride & Ride sharing, Bike sharing & Car, motorbike \\
\hline 9 & rapido & Bike sharing & Motorbike \\
\hline 10 & rpool & Ride sharing, Bike sharing & Car, motorbike \\
\hline 11 & vogo & Bike sharing & Motorbike, bicycles \\
\hline 12 & pedl & Bike sharing & Bicycles \\
\hline
\end{tabular}

\section{METHODOLOGY}

\subsection{Study area}

Bangalore was chosen as the study area as it is one of the prominent metropolises in India and well as Asia. Its population of 8.6 million is representative of the major cities in Asia like Bangkok (8.2 million), Seoul (9.9 million), Lahore (10 million) and Mumbai (12.4 million). The city is India's Silicon Valley, and attracts people from all across the 
country. Planning for mobility is an important aspect of a growing metropolis, and Bangalore appears to be excellent for exploratory research.

\subsection{Survey design and implementation}

The purpose of this research is to document shared mobility characteristics in metropolis, which has been well documented using user survey in several studies [13], [14]. A 25 question survey was designed, to understand preferences of mobility in the context of Bangalore. A combination of close-ended questions (multiple selection, linear scale) and open-ended questions were included. The survey instrumented was pre-tested with eight pilot surveys and modified slightly based on user feedback.

Convenience sampling method was used for the survey implementation which is an established method in exploratory surveys. A database of users, proprietary to our company was used to disseminate the survey. Google forms, a freely available software was chosen as the platform to reach the respondents. The forms were emailed to 2,000 potential respondents whom we assumed to be residents of Bangalore or frequent and occasional visitors to the city.

\subsection{Results}

Out of 2,000 forms sent out, 230 completed surveys were received, which is about $11.5 \%$ response rate. Out of 230, we used 218 for analysis. The rest (12) were removed due to noncompliance of the key criteria, i.e. being resident of Bangalore Metropolitan Area or visitors of the city. Considering ethics of research, we did not collect any personal information such as name or other identifiers. The responses were found to be reasonably well distributed spatially, across age groups, working groups, income groups and gender groups. The responses were exclusively from residents and visitors of the city which further strengthened the results. The responses were hence considered as representative of the user base in the city for the purpose of exploratory research.

\section{RESULTS OF SURVEY}

\subsection{Respondent demographics}

$90 \%$ of the survey respondents were residents of Bangalore and about one third of the total respondents were female. The survey sample was found to be skewed in terms of sex ratio, age distribution and employment status compared to that of the city as a whole. However, the samples corresponded perfectly to the car ownership (Table 3).

Majority of the surveyed population was employed. The income level of the respondents was found to be higher than the average income level in Bangalore which is around INR 3.8 lakhs per annum. $86 \%$ of the respondents reported owning a vehicle of which about $69 \%$ owned multiple vehicles.

\subsection{Trip origins and destinations}

The trip origin and destinations of the respondents were converted into an OD diagram (Fig. 1). The survey was able to capture a reasonably uniform distribution of trips all across Bangalore. A considerable number of trips were made outside the city limits, mostly to the international airport in the north. 
Table 3: Respondent demographics.

\begin{tabular}{|c|c|c|c|}
\hline \multirow{2}{*}{ Indicators } & \multicolumn{2}{|c|}{ Survey } & \multirow{2}{*}{$\begin{array}{c}\text { Bangalore city } \\
\text { statistics }\end{array}$} \\
\hline & Survey response & Percentage & \\
\hline \multicolumn{4}{|l|}{ Gender } \\
\hline Male & 151 & $70 \%$ & $52 \%$ \\
\hline Female & 65 & $30 \%$ & $48 \%$ \\
\hline $\mathrm{n}$ & 216 & & \\
\hline \multicolumn{4}{|l|}{ Resident status } \\
\hline Resident & 197 & $90 \%$ & \\
\hline Frequent visitor & 11 & $5 \%$ & \\
\hline Occasional visitor & 10 & $5 \%$ & \\
\hline $\mathrm{N}$ & 218 & & \\
\hline \multicolumn{4}{|l|}{ Age (years) } \\
\hline $15-20$ & 5 & $2 \%$ & $8 \%$ \\
\hline $20-30$ & 36 & $17 \%$ & $23.00 \%$ \\
\hline $30-40$ & 91 & $42 \%$ & $18.00 \%$ \\
\hline $40-50$ & 42 & $19 \%$ & $13.00 \%$ \\
\hline$>50$ & 43 & $20 \%$ & $19.50 \%$ \\
\hline $\mathrm{n}$ & 217 & & \\
\hline \multicolumn{4}{|l|}{ Employment status } \\
\hline Employed & 145 & $67 \%$ & $44.14 \%$ \\
\hline Unemployed & 73 & $33 \%$ & $55.86 \%$ \\
\hline $\mathrm{n}$ & 218 & & \\
\hline \multicolumn{4}{|c|}{ Income (INR, Lakhs per annum) } \\
\hline$<5(\$ 7142)$ & 46 & $25 \%$ & \\
\hline $5-10(\$ 7142-\$ 14,285)$ & 48 & $26 \%$ & \\
\hline $10-15(\$ 14,285-\$ 21,428)$ & 39 & $21 \%$ & \\
\hline$>15(>\$ 21,428)$ & 51 & $28 \%$ & \\
\hline $\mathrm{n}$ & 184 & & \\
\hline \multicolumn{4}{|l|}{ Vehicle ownership } \\
\hline Yes & 191 & $86 \%$ & $84 \%$ \\
\hline No & 31 & $14 \%$ & $16 \%$ \\
\hline $\mathrm{n}$ & 212 & & \\
\hline \multicolumn{4}{|l|}{ Vehicle owned } \\
\hline Car & 59 & $31 \%$ & \\
\hline Electric car & 1 & $1 \%$ & \\
\hline Motorcycle & 131 & $69 \%$ & \\
\hline Electric scooter & 0 & $0 \%$ & \\
\hline $\mathrm{n}$ & 191 & & \\
\hline \multicolumn{4}{|l|}{ No of vehicles owned } \\
\hline Single vehicle & 59 & $31 \%$ & $60 \%$ \\
\hline Multiple vehicles & 132 & $69 \%$ & $20 \%$ \\
\hline $\mathrm{n}$ & 191 & & \\
\hline
\end{tabular}




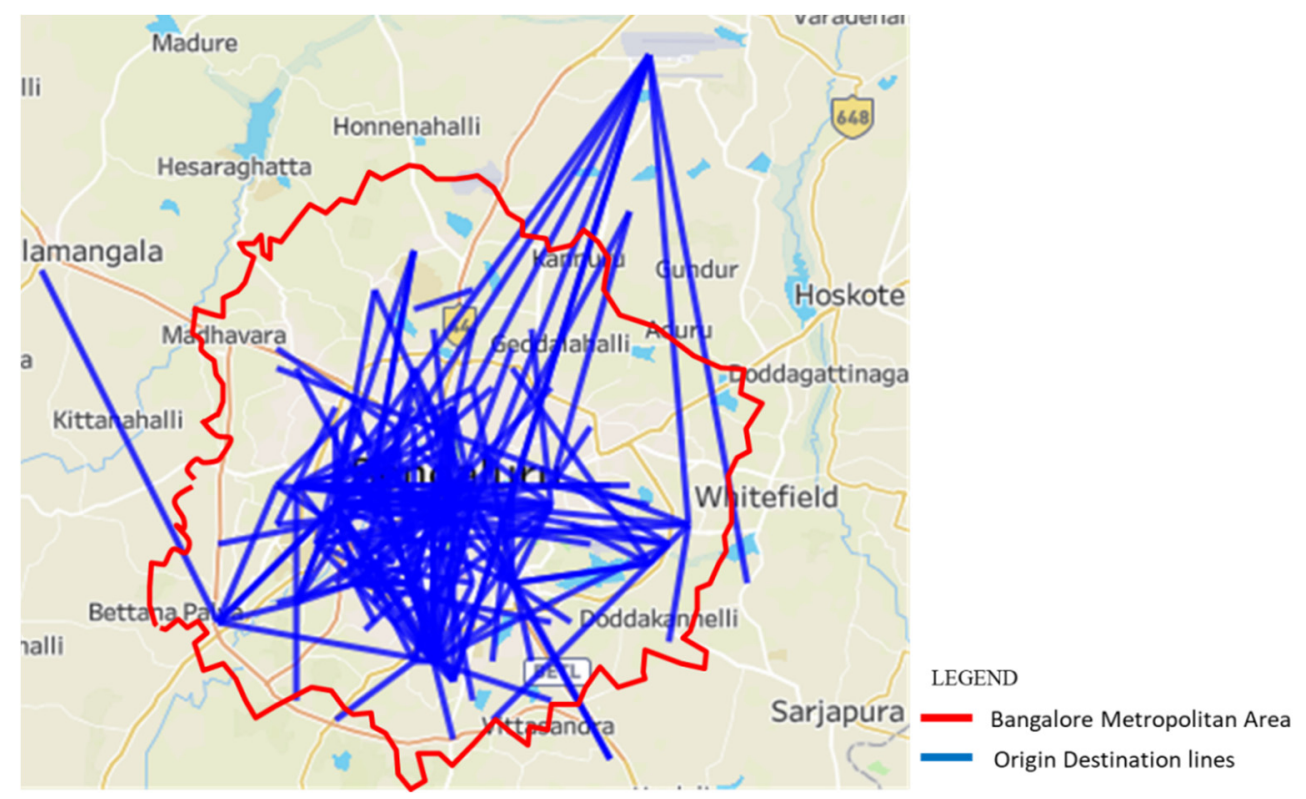

Figure 1: Trip origin and destinations using shared modes.

Trip distribution by service provider

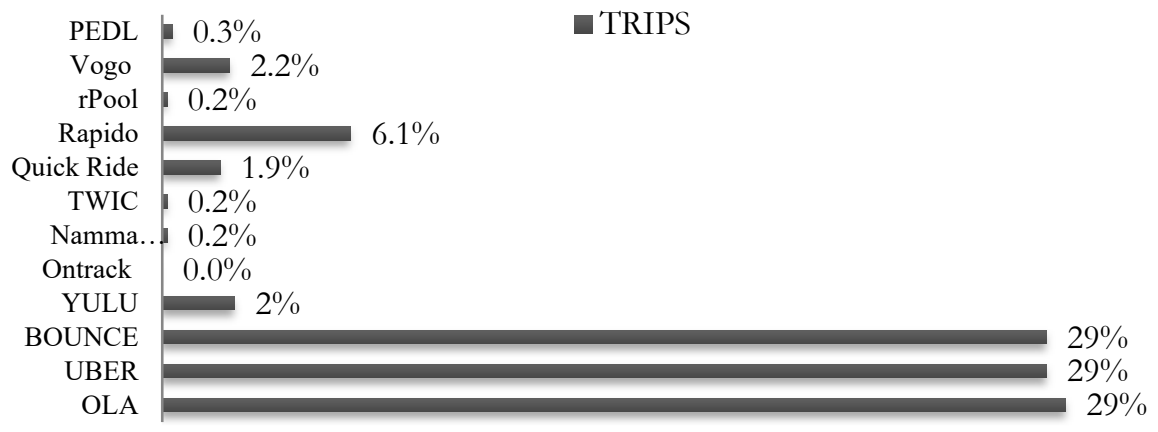

Figure 2: Trip distribution by service providers.

\subsection{Choice of service provider}

Ola, Uber and Bounce were found to be most frequently used by the respondents as seen in Fig. 2. 87\% if all trips were made using vehicles from these services.

Cars, motorbikes and autorikshaws were found to be the dominant modes of transport in the shared mobility market. It was found that $41 \%$ of the trips through Ola were completed using autorikshaws while users of Uber used mostly car. Among Bounce users, $95 \%$ of the trips were completed using motorbike while $5 \%$ were completed using e-motorbikes. 


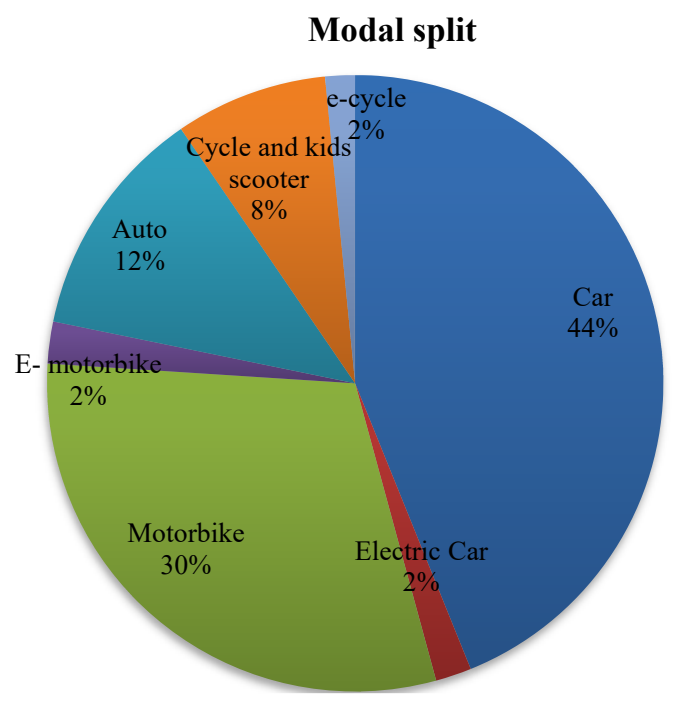

Figure 3: Modal split.

Share of public transport in Bangalore is $48 \%$, cars and taxis constitute $21 \%$, autorikshaws consist of $8 \%$ and two wheelers constitute $24 \%$ of the total vehicles in the city (Fig. 3). Share of cars appeared higher in the survey result which may be attributed to the higher fleet size of cars in the shared mobility market.

$41 \%$ of the survey respondents reported collecting the vehicles from a docking station. Only $8 \%$ of the respondents reported poor maintenance of the vehicles. Vehicle availability was reported to be satisfactory about $78 \%$ of the times. Respondents reporting unsatisfactory vehicle availability were mostly clustered in the western part of the city.

\subsection{Trip characteristics}

Trip characteristics were studied through indicators like trip purpose, trip length and duration. It was found that almost half (53\%) of the trips were taken for work purpose. $18 \%$ of the respondents also reported using these services for emergency purposed. However about $66 \%$ of the respondents were not frequent users of shared mobility, using them less than twice per week. $40 \%$ of the users reported using shared mobility as a first-mile or last-mile connectivity along with public transport as seen in Fig. 4.

Close to half of the trips lengths reported from the survey were more than $10 \mathrm{~km}$ as shown in Fig. 5. The average trip length in Bangalore city for car travel is $10.1 \mathrm{~km}$ while than by taxi is $13.1 \mathrm{~km}$ [15]. There was no significant correlation found between trip purpose and trip length. Trip length distribution was similar for all trip purposes.

Majority of the trips $(70 \%)$ were undertaken during the morning and evening peak hours. About $64 \%$ of the trips were of 30 minutes to 1 hour duration as see in Fig. 6. The longer duration trips mostly originated in the outer areas of the city and travelled in high density corridors or across the city. Majority of the respondents reported spending between INR 100INR $200(\$ 1.4-\$ 2.4)$ per trip as seen in Fig. 7. The trips with higher expenditure corresponded to the longer duration trips. However, it was unclear if the expenditure as strongly correlated with the mode used. 


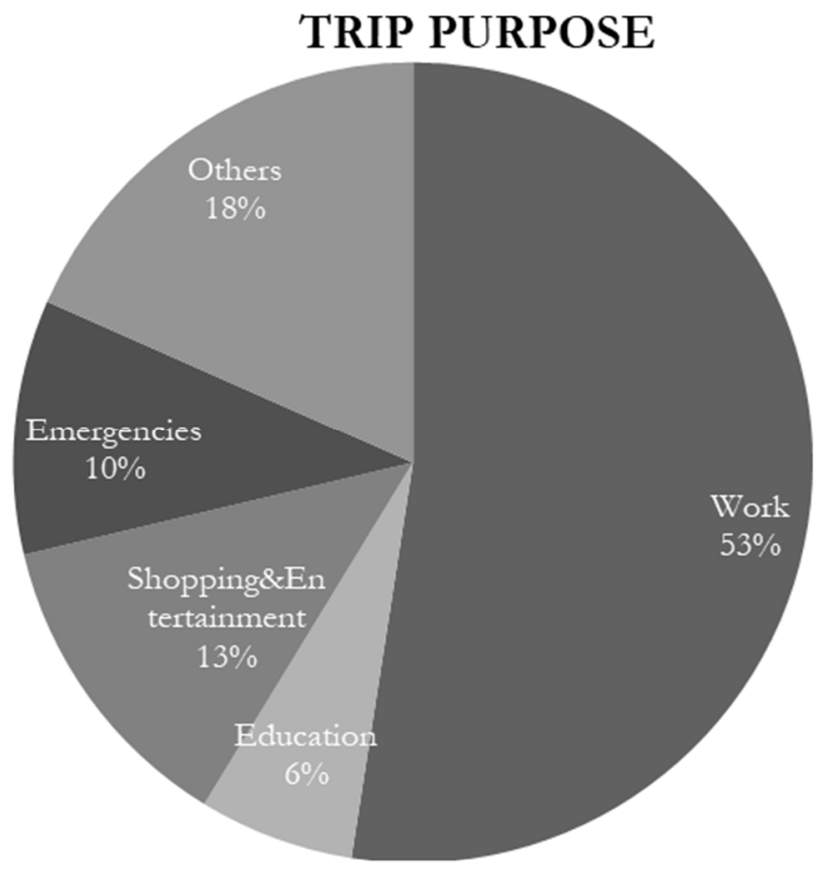

Figure 4: Trip purpose.

\section{TRIP LENGTH}
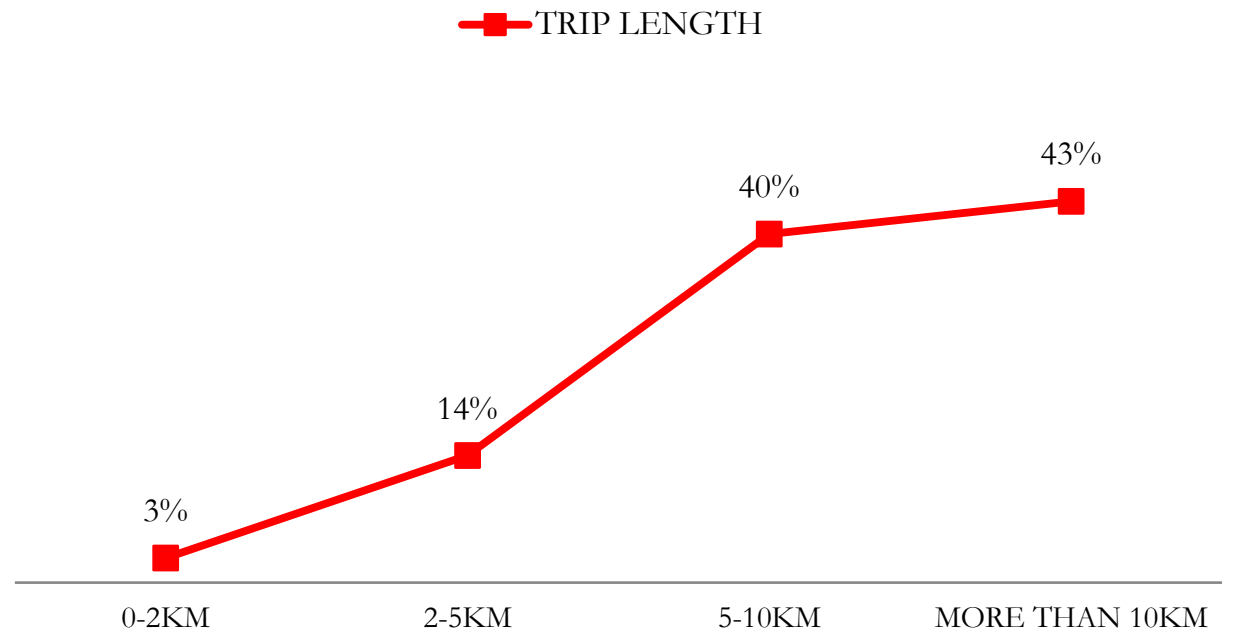

Figure 5: Trip length. 


\section{TRIP DURATION}

$\leadsto$ TRIP DURATION

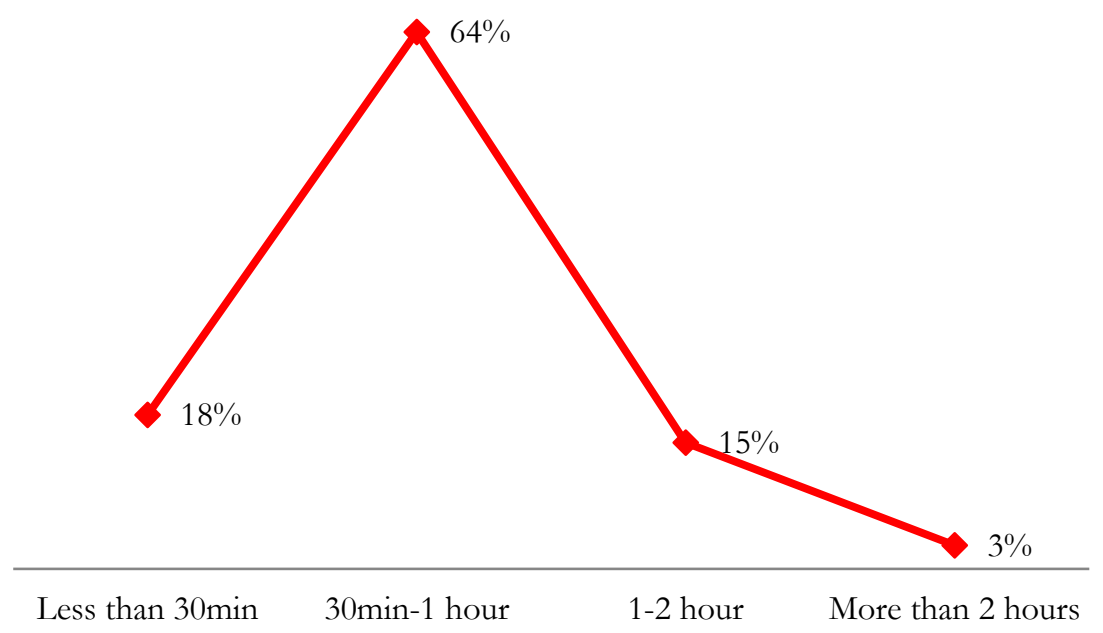

Figure 6: Trip duration.

\section{TRIP EXPENDITURE}

$\smile$ EXPENDITURE

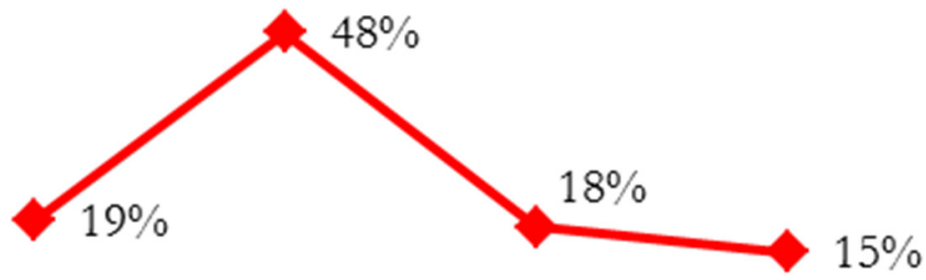
less than INR INR 100 - INR 200 - More than
$100 \quad 200 \quad 300 \quad$ INR 300
$(\$ 1.4) \quad(\$ 1.4-\$ 2.4) \quad(\$ 2.4-\$ 3.4)$
$(\$ 3.4)$

Figure 7: Expenditure per trip. 
Shared mobility was largely perceived to be safe. In a scale of 1 to 5, with 5 being "very safe", majority of the respondents reported feeling safe to very safe using these services. The perception did not appear to be gender biased. However, $69 \%$ of the respondents who reported feeling safe used cars from these service providers. About $50 \%$ of these respondents used the services for work and but were not frequent users of the service as seen in Fig. 8.

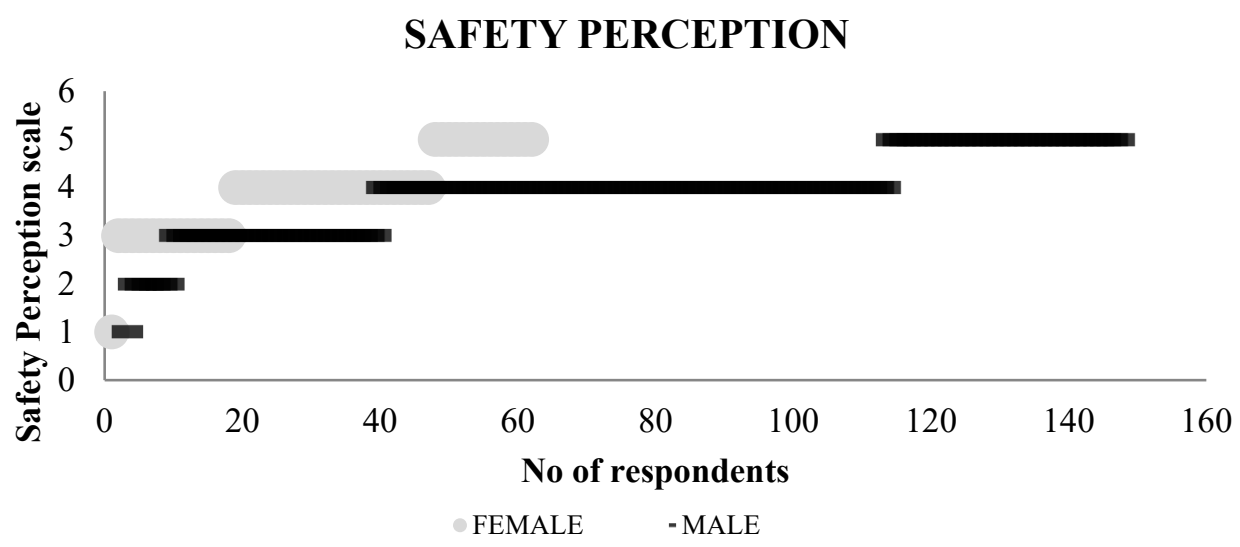

Figure 8: Safety perception of respondents.

\section{INFERENCE}

The study highlights that shared mobility is one of the significant modes of movement in Bangalore. Shared mobility is often perceived as a choice for young and smart phone equipped population. However, the study found that there is no specific bias towards use of these services from any particular age group. The services were found to be used equally by users of all age group. It is also established that the services are popular with all economic classes and genders. Both male and female respondents report similar patterns of use and satisfaction level.

A significant part of the responses also highlight use of shared mobility as first-mile or last-mile connectivity along with public transport. The services appeared to be expensive as a permanent means of travel. The average monthly expenditure by usage of shared mobility is projected to be INR 7,500 (\$107)whereas average expenditure in Bangalore on transport is INR 2,473 (\$35) per month [15]. Hence price point of the services appeared as one of the important points for consideration.

The market is dominated by Ola, Uber and Bounce, which can be attributed to the larger fleet size owned by these service providers and faster access to these vehicles. Also, the nonmotorised transport sector still has a smaller market share in India; hence operators in operating with non-motorised modes have lesser share of the market. The use of cars and motorbikes can also be attributed to the longer trip lengths which is less preferred in the Bangalore climate as well as the road and traffic situation.

Shared mobility is perceived to be safe, majorly by respondents of car use. It is not clear if the lack of safety for other mode users is due to road safety factors or social and crime related factors. 


\section{CONCLUSION}

The paper established that important role being played by shared mobility in the landscape of Bangalore. The possibilities in terms of providing efficient transportation, sustainable environment and achieving social equity are enormous. Shared modes have the potential to play a complimentary role to public transportation by facilitating first-mile and last-mile connectivity. Shared modes are also more sustainable than private modes. They can play a significant role in India's commitment to reduction of carbon footprint and green house has emissions. Planned inclusion of shared mobility in the transportation plan of the city is imperative to draw its benefits. The role of shared mobility in achieving social equity should also be explored. It would have a significant role in the India's affordable housing market by opening up serviced lands in the city periphery when coupled with mass transportation.

The present research is exploratory in nature and is one of the first documented studies in the shared mobility scenario in India cities. The survey was found to be reasonably well distributed spatially, across age groups, working groups, income groups and gender groups. The responses were exclusively from residents and visitors of the city which further strengthens the results. Bangalore being one of the most dynamic metropolises of the country also served as a good study area for an exploratory study of shared mobility characteristics at the city level. The study can hence be used for developing and testing hypothesis for Bangalore as well as other Indian cities as well.

Further research is recommended to accurately document the role of shared mobility in the areas of transportation, sustainability and affordable housing in Bangalore and other Indian cities. Such studies can help in developing holistic policy documents for cities to guide transport infrastructure, policy and operation guidelines, sustainable development and affordable housing policies.

\section{ACKNOWLEDGEMENTS}

I would like to acknowledge the incremental benefits that I have drawn throughout my life from the education and values inculcated by my parents Bimalendu and Tapati. To them I would be forever grateful. For their support over the last half a decade, I thank my parentsin-law Hamsa and Mahesh. My brother, Rahul, whose constant search for meaning has made me strive as well. My husband, Akash, who has been my colleague, friend, advisor and sounding board and without him none of this would have been possible. And last but not the least our son, Samak, whose smile makes everything worth the toll.

\section{REFERENCES}

[1] Strategic Assessment of Shared Mobility Market in India, Frost and Sullivan, Sep. 2019.

[2] The World Bank, Data Bank, Data for India. https://data.worldbank.org/?locations=IN-1W. Accessed on: May 2020.

[3] The World Bank Data Bank, India Indicator. https://data.worldbank.org/indicator/sp.urb.totl.in.zs. Accessed on: May 2020.

[4] Study of Traffic and Transportation Policies and Strategies in Urban Areas in India, Ministry of Urban Development, India (MoUD) and WSA, 2008.

[5] Financial Express, India's crude oil import bill halves to \$64 billion in 2015-2016, 2016.

[6] Ghate, A. \& Sundar, S., Can we reduce the rate of growth of car ownership. Economic and Political Weekly, Jun. 2013.

[7] Shaheen, S., Bell, C., Cohen, A. \& Yelchuru, B., Travel behaviour: Shared mobility and transportation equity, Federal Highway Administration, 2017. 
[8] Shaheen, S., Cohen, A. \& Martin, E.U.S., Department of Transportation's Mobility on Demand Initiative: Moving the economy with innovation and understanding. Transportation Research Circular: Washington, DC, 2018.

[9] Dias, F.F., Lavieri, P.S., Garikapati, V.M., Astroza, S., Pendyala, R.M. \& Bhat, C.R., A behavioral choice model of the use of car-sharing and ride-sourcing services. Transportation, 44, pp. 1307-1323, 2017.

[10] Shared Mobility and the Transformation of Public Transit, TCRP Research Report 188, Transportation Research Board, 2017.

[11] The State of European Car-Sharing Final Report, D 2.4 Work Package 2, Bundesverband Car Sharing e.V., Jun. 2010.

[12] Arcidiacono, D. \& Pais, I., Think mobility over: A survey on Car2go users in Milan. Multidisciplinary Design of Sharing Services, ed. M. Bruglieri, Springer, 2017.

[13] Circella, G. et al., The Adoption of Shared Mobility in California and Its Relationship with Other Components of Travel Behavior, UC Davis, 2018.

[14] Shaheen, S. \& Chan, N., Mobility and the Sharing Economy: Potential to Overcome First- and Last-Mile Public Transit Connections, UC Berkeley, 2016.

[15] Comprehensive Mobility Plan for Bengaluru (draft), Bangalore Metro Rail Corporation Ltd and Directorate of Urban Land Transport, GoK, 2019. 